Koster, E.S., Philbert, D., Dijk, L. van, Vries, T.W. de, Bouvy, M.L. “I just forget to take it”: asthma self-management needs and preferences in adolescents. Journal of Asthma: 2015, 52(8), 831-837

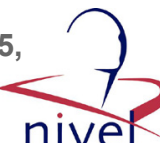

\begin{tabular}{|l|l|}
\hline $\begin{array}{l}\text { Postprint } \\
\text { Version }\end{array}$ & 1.0 \\
\hline Journal website & http://informahealthcare.com/doi/abs/10.3109/02770903.2015.1020388 \\
\hline Pubmed link & $\underline{\text { http://www.ncbi.nlm.nih.gov/pubmed/?term=26037397 }}$ \\
\hline DOI & $10.3109 / 02770903.2015 .1020388$ \\
\hline
\end{tabular}

This is a NIVEL certified Post Print, more info at http://www.nivel.eu

\title{
"I just forget to take it": asthma self-management needs and preferences in adolescents
}

\author{
Ellen S. Koster, Daphne Philbert, TJalling W. DE VRIES, Liset VAN DiJK, AND \\ MARCEL L. BOUVY \\ ${ }^{1}$ Division of Department of Pharmacoepidemiology and Clinical Pharmacology, Utrecht \\ Pharmacy Practice Network for Education and Research (UPPER), Utrecht University, \\ Utrecht, The Netherlands, \\ ${ }^{2}$ Department of Pediatrics, Medical Centre Leeuwarden, Leeuwarden, The Netherlands, \\ and \\ ${ }^{3}$ Netherlands Institute for Health Services Research, Utrecht, The Netherlands
}

\begin{abstract}
Background: Medication adherence rates often decline as children become teenagers. Effective adherence-enhancing interventions for adolescents are lacking. The objective of this study was to assess adolescent asthmatics needs and preferences regarding medication counseling and support, with focus on new media. Methods: Three focus groups including 21 asthmatic adolescents recruited from both primary and secondary care were held to explore needs and preferences regarding asthma-self management. Questions concerned adherence behavior and needs and preferences in adherence support with focus on new media (mobile technology, social media, health games). Results: Forgetting was mentioned as major reason for not using medication as prescribed. Adolescents also mentioned lack of perceived need or beneficial effects. Parents mainly play a role in reminding to take medication and collecting refills. The suggested strategies to support self-management included smartphone applications with a reminder function and easy access to online information. Participants were positive about sharing of experiences with other teenagers. Conclusion: Forgetfulness is a major reason for non-adherence in adolescents. Furthermore, our results suggest use of peer support may be helpful in promoting good medication use. Future interventions should be aimed at providing practical reminders and should be modifiable to individual preferences.
\end{abstract}

\section{INTRODUCTION}

Medication non-adherence is often a concern in children and adults, but little attention is paid to adolescents [1,2], whilst we know adherence rates often decline as 
Koster, E.S., Philbert, D., Dijk, L. van, Vries, T.W. de, Bouvy, M.L. “I just forget to take it”: asthma self-management needs and preferences in adolescents. Journal of Asthma: 2015, 52(8), 831-837

children become teenagers $[3,4]$. Poor adherence can lead to uncontrolled disease and severely affect quality of life [5]. The observed decline in medication adherence during adolescence is not surprising as this potentially turbulent phase is associated with physical, cognitive and social changes. Adolescents develop their identity and start making their own decisions. During this period there are school transitions, adolescents choose after-school activities. Peers increasingly play a role in their life. These changes may affect (chronic) medication use [6]. Adherence is a multidimensional healthcare problem and there is not one solution that fits all patients [7]. Interventions should therefore be tailored to patients' individual needs and underlying reasons for non-adherence. To our knowledge, there is no consistent evidence for effective interventions in (asthmatic) adolescents [8].

Adolescents often have busy schedules as well as difficulties with planning; it is therefore important to find ways to improve medication adherence behavior that will easily fit into their daily life. Modern technologies are increasingly used to facilitate self-management and encourage adherence. Examples are text message reminders, smartphone applications, use of health games, as well as websites with educational materials or online diaries [9-13]. Previous research showed that use of these technologies may improve disease outcomes in adolescents $[12,14]$. However, to date there is still limited use of new media in intervention development, whilst patients are in general positive about the potential of these solutions $[15,16,18]$.

Adolescents seem to be highly engaged in new technologies and frequently communicate through mobile or social media, therefore solutions based on new media seem suitable for this group. We sought to assess adolescents' needs and preferences regarding medication counseling and support with special focus on new media.

\section{MATERIALS AND METHODS}

Adolescents' needs and preferences regarding asthma self-management and adherence support were examined by means of focus groups. First, two online focus groups were conducted (December 2013) and second, a traditional face-to-face focus group (March 2014) was conducted.

\section{Setting and population}

Eligible adolescent inhaled corticosteroid users (ICS) were invited from community pharmacies affiliated with the Utrecht Pharmacy Practice network for Education and Research (UPPER) to participate in an online focus group [19]. Inclusion criteria were: age between 12 and 16 years and filling of at least two ICS prescriptions during the last two years of which at least one prescription was filled during the previous year. By using these criteria, we excluded patients who used asthma medication as a first prescription trial (which usually starts with a prescription for a short-acting beta-agonist). Selected patients were sent an information brochure and the request to return informed consent within two weeks. With this procedure we aimed at recruitment of 6-10 participants for two separate online focus groups: early adolescence (age 12-13 years) and late adolescence (age 14-16 years), as there may 
Koster, E.S., Philbert, D., Dijk, L. van, Vries, T.W. de, Bouvy, M.L. “I just forget to take it”: asthma self-management needs and preferences in adolescents. Journal of Asthma: 2015, 52(8), 831-837

be difference in perceptions and cognitive and social-emotional development between these two age groups. The study was conducted in compliance with the requirements of the UPPER Institutional Review Board of the Division of Pharmacoepidemiology and Clinical Pharmacology, Utrecht University.

Second, adolescent patients were invited from the Department of Pediatrics at the Medical Centre Leeuwarden for participation in a traditional face-to-face focus group. Inclusion criteria were: age between 12 and 16 years, having a physician diagnosis of asthma and current medication use. Selected patients were sent an information brochure containing information about the study and the request to return informed consent within two weeks, aiming at recruitment of 6-10 participants for a focus group (age 12-16 years). This part of the study was approved by the Institutional Review Board of the Medical Centre Leeuwarden.

\section{Procedures}

The online focus group method, developed for a pediatric population by the Netherlands Institute for Health Services Research (NIVEL), has shown to be a feasible tool for collecting qualitative data within young populations [20]. The online focus groups were conducted in an asynchronous form over a one-week period (December 2013). Participants could respond and read others' comments at any time, not necessarily when anyone else was participating. All participants received individual login names and passwords to anonymously access the focus group website during the one-week study period.

The online focus groups were guided by a topic list (Table 1). Topics were based on our own previous research (interviews with pharmacy staff) [21] and literature review $[6,8,12,14-16,22]$. Questions concerned adherence behavior in general and needs and preferences in adherence support with special focus on new media (e.g. mobile technology, social media and health games). A new question or statement was introduced by the moderators (EK or DP) on each of the first five days and on day six and seven participants could introduce new issues themselves or respond to the questions of the previous days. Every day, participants received an e-mail reminder when a new statement had been placed on the website. Participants were asked to respond anonymously to these questions introduced by the researcher and to each other's comments. The moderators provided prompts to pursue more detailed discussions for some topics and to keep the discussions on track. Participants received a $€ 15$ gift card incentive for participation in the online focus groups.

\section{[TABLE 1]}

The traditional face-to-face focus group was moderated by two researchers (EK and $\mathrm{TdV}$ ) and another researcher assisted and took notes (DP). Every new topic was introduced by a statement or question. Participants were asked to describe their thoughts and feelings and react on each other's comments. The moderators only provided prompts to stimulate more detailed discussions. During this focus group, similar topics were discussed compared to the online focus groups based on a topic 
Koster, E.S., Philbert, D., Dijk, L. van, Vries, T.W. de, Bouvy, M.L. “I just forget to take it”: asthma self-management needs and preferences in adolescents. Journal of Asthma: 2015, 52(8), 831-837

list (Table 1). Participants received a $€ 15$ gift card incentive for participation in the focus group which lasted approximately $90 \mathrm{~min}$.

\section{Data analysis}

Discussions from the online focus group were extracted from the focus group website in a Microsoft Excel worksheet. The traditional face-to-face focus group was audiotaped and transcribed. Inductive thematic analysis was used to analyze the focus group transcripts [23], consisting of two steps: (1) coding of the (raw) data and (2) interpretation of the codes/themes. We used an inductive data-driven approach, e.g. coding was performed without trying to fit the focus group data into a preexisting model or framework, to enable a rich description of the overall data. Segmentation and coding started from an initial coding list. This list was tested and further adapted. We developed a set of themes that captured the essence of the focus group discussions. To this end, two investigators (EK and DP) coded the text elements manually independently from each other, compared their findings and through discussion, un-clarities were resolved and additional codes were added. When all text segments were coded, a summary was made per participant.

\section{RESULTS}

\section{Characteristics of participants}

In total, 192 adolescents were selected from 13 community pharmacies and requested for their participation in the online focus groups. Fourteen (seven younger (age 1213 years) and seven older (age 14-16 years) adolescents) returned informed consent within a two-week period and participated. During the one-week study period, these 14 participants placed 110 reactions for the different themes. Older participants were more actively engaged in the discussions ( 74 reactions versus 36 reactions during a one-week period). For the traditional face-to-face focus group, 60 adolescents were invited, of which seven returned informed consent within a two-week period and participated. Table 2 shows characteristics of participants. In total, 21 adolescents participated, 9 younger adolescents (43\%) aged 12-13 years and 12 older adolescents (57\%) aged 14-16 years. Most participants were of native Dutch origin (86\%). Focus group participants were not different with respect to age and gender compared to those we were not able to recruit (data not shown).

\section{[TABLE 2]}

Results for the four major themes, discussed during both the online and traditional focus group - (1) adherence, (2) role of parents, (3) solutions to support medication use and (4) new media as solution - are listed in Tables 3 and 4. We did not observe differences in responses between the two types of focus groups (online vs. traditional), therefore results were analyzed jointly.

\section{[TABLE 3][TABLE 4]}

\section{Meaning of asthma and impact in daily life}


Koster, E.S., Philbert, D., Dijk, L. van, Vries, T.W. de, Bouvy, M.L. “I just forget to take it”: asthma self-management needs and preferences in adolescents. Journal of Asthma: 2015, 52(8), 831-837

The traditional focus group started with a question to describe the impact of asthma in the daily lives of the participants (this question was not asked during the online focus group, Table 1). For most adolescents, asthma was associated with limitations in daily activities, such as sports. Participants also mentioned the feeling of being different from their classmates and two adolescents mentioned lack of understanding of their peers or even bullying at school.

\section{Major theme 1: adherence - reasons for not using medication as prescribed}

Forgetting to take medication was mentioned as most important reason for not using medication as prescribed by both younger (four out of nine participants) and older adolescents (6 out of 12) (Table 3). Most of the adolescents could give reasons for forgetting to take medication: they were in a hurry for school in the morning and during the weekends or during holidays forgetting of medication was more common according to some of the respondents. They also mentioned they are often just busy with other things than taking their medicines. Furthermore, some adolescents mentioned it is not always easy to use mediation outside home (at school) and some doubted the necessity of medication.

There are moments I do not feel better from using my inhaler, those times I use nothing.

(girl, aged 14, traditional focus group)

\section{Major theme 2: role of parents}

For most participants (both older and younger adolescents), parental support consists mainly of reminding them to take their medication $(n=12)$, support in picking up prescriptions at the pharmacy $(n=9)$ and joining them during physician consultations $(n=8)$ (Table 3$)$. There seem to be no differences between younger and older participants in parental support. In addition, only one participant mentioned the supportive role of her friend in using medication.

I can take my medicines by myself, but my parents remind me of taking the medicines and they fill prescriptions at the pharmacy. I always talk to the pediatrician or asthma nurse together with my parents.

(boy, aged 13, online focus group)

My parents order my medicines and ask me sometimes about my medicines. That's all, I have no need for further support from them.

(boy, aged 15, online focus group)

\section{Major theme 3: solutions to support medication use}

The adolescents participating in this study did not use many special tools to support their daily medication regimen (Table 4). Only one participant mentioned the use of an alarm as a reminder (major theme 1) to take his medicines on time. Most of the participants mentioned they put their medicines in a fixed place, such as the 
Koster, E.S., Philbert, D., Dijk, L. van, Vries, T.W. de, Bouvy, M.L. “I just forget to take it”: asthma self-management needs and preferences in adolescents. Journal of Asthma: 2015, 52(8), 831-837

bathroom or kitchen table, in order to see the medication every day to remind them. This seemed especially true for older adolescents. Some carried their inhaler always with them (in their bag) and some adolescents said they did nothing special to support the daily medication intake.

I always put my medicines in the same place (on the kitchen table), that way I think of it when I walk by: Hey, I haven't used my inhaler yet.

(girl, aged 15, traditional focus group)

I put my medicines under my pillow, that way I will not forget to take them in the morning when I wake up.

(girl, aged 16, traditional focus group)

\section{Major theme 4: new media as solution to support medication use}

In general, the adolescents did not have many ideas how to improve the irregular use of their medication. They found it difficult to come up with concrete solutions (Table 4). Some adolescents mentioned reducing the dosing frequency throughout the day, e.g. taking only once a day medication instead of twice a day. A smartphone application (app) with the possibility to personalize settings, such as type of inhaler was suggested as solution during the online focus groups. Also during the traditional focus groups, adolescents spontaneously mentioned an app to facilitate asthma selfmanagement. In addition, we asked them specific feedback about what such an app should look like. The most important feature should be a reminder function (major theme 1). Adolescents all had a smartphone that they always carried with them and therefore they thought an app would be an easy tool.

A sort of alarm would help. It is about taking your medicines on time, that way your parents don't have to remind you all the time (they also think I should do it myself).

(boy, aged 12, traditional focus group)

We also asked the participants' opinion about a health game as possible intervention to improve adherence and facilitate asthma self-management. Most of them thought a game would not help them $(n=12)$, this was especially true for the older respondents ( 8 out of 12). Some of them mentioned a game could be a fun way to learn something about disease or medication, however, most participants thought a game would be more suitable for (younger) children.

A game will be boring after a while.

(girl, aged 16, traditional focus group)

A game might be fun, but is more suitable for younger children, at the age of 7 or something.

(girl, aged 13, online focus group) 
Koster, E.S., Philbert, D., Dijk, L. van, Vries, T.W. de, Bouvy, M.L. “I just forget to take it”: asthma self-management needs and preferences in adolescents. Journal of Asthma: 2015, 52(8), 831-837

Also, use of online information, such as instruction movies about medication or education material on disease (asthma) was mentioned by some of the participants. Furthermore, all participants valued sharing of information with other patients - this was mentioned as additional comment - and some mentioned WhatsApp as example to communicate with other patients or even easily contact a healthcare provider.

\section{Participation in the study}

During the last two days of the data collection period of the online focus groups and during the last discussion round of the conventional focus group, participants were invited to introduce other issues. Many participants commented positively on participation in the study and mentioned that sharing of experiences with other patients was appreciated. Furthermore, they provided supportive comments regarding the study and the use of the focus group methodology.

It is good to know that I am not the only one who forgets the medicines.

(girl, aged 14, online focus group)

It was fun to participate in this study and to experience how fellow patients think and cope with their disease. I think that is important, the questions were good and it was good to realize things.

(boy, aged 15, traditional focus group)

\section{DISCUSSION}

The main objective of this study was to gain insight in adolescents' thoughts regarding needs and preferences and the role of new media in asthma selfmanagement. The patients in this study expressed their views regarding this topic and the study showed three main subjects for discussion: (1) forgetting seems to be the most important reasons for non-adherence, (2) parents still play an important supportive role and (3) adherence support should be preferably delivered through mobile phone technology.

There was unanimity among participants with respect to their reasons for nonadherence. In line with previous research in adolescent patient populations, forgetting was mentioned as most important reason for not using medication as prescribed [24,25]. Forgetting may be due to several reasons: adolescents are often busy with other things and don't choose to make time to take their medicines in some cases, their organizing skills are still in development or they might forget medication on purpose (because they are ashamed) [26]. Furthermore, lack of perceived effect and difficulties to incorporate medication use in daily life (use of medicines at school) were mentioned.

Roles will change when children grow older [4], we therefore asked participants about the supportive roles of their parents. We observed some differences between participants in supportive roles of parents (however no real differences between 
Koster, E.S., Philbert, D., Dijk, L. van, Vries, T.W. de, Bouvy, M.L. “I just forget to take it”: asthma self-management needs and preferences in adolescents. Journal of Asthma: 2015, 52(8), 831-837

younger and older participants). Some adolescents tended to report a broader spectrum of supportive tasks for their parents, whilst older adolescents mentioned to be more independent (e.g. parents only involved in filling of prescriptions or joining in physician consultations). In line with previous research, both younger and older adolescents in this study reported a supportive role for their parents [22,26]. Parents were mainly involved in reminding their child to take the medicines and are often responsible for filling prescriptions in the pharmacy. However, in contrast to some of the studies discussed in the review paper by Hanghoj and co-workers [26] who described the possible negative influence of parents on adherence the adolescents in our study mainly talked about the positive supportive role of their parents and factors such as family stress. Bad home environment or conflicts between parents and adolescents were not mentioned (also no specific goal of this study). Support of peers in asthma self-management was not mentioned during the focus group discussions, however most participants valued sharing of (online) experiences with other adolescent patients.

During the focus groups different solutions to support medication, intake behavior were discussed (e.g. health games, social media and smart phone applications). The adolescents in this study thought that a (health) game would be more suitable for (younger) children. They mentioned an intervention should be easy to use and an important feature should be reminding them to take medication. Adolescents preferred adherence support delivered through mobile phone technology, e.g. use of apps. Stewart et al. also assessed needs and preferences of adolescents with asthma and allergies and also described need for user-friendly support through interactive websites with messaging tools [22]. Van der Meer et al. [27] assessed effectiveness of an internet-based self-management program for adolescents with asthma and showed positive effects on asthma control. Mobile phone applications are increasingly used in healthcare settings to support patients [28]. A study of Mulvaney and co-workers, aimed at the use of mobile phone technology in assessing symptoms and adherence, found this a useful method to provide information on symptoms and adherence in adolescent populations [29].

One of the strengths of this study is the use of a qualitative design. Focus group discussions have been recommended in research involving pediatric populations, as this data collection method allows the participants to use their own words in formulating responses [30]. It was not well understood how adolescents with asthma would value interventions based on new media. By using a combined approach of both online and traditional face-to-face focus groups, we provided in depth perspectives of a group of adolescents coping with daily medication use for asthma. Compared to face-to-face interviews or traditional focus groups, online focus groups have the advantage participants can join the discussions at any convenient moment. The high level of anonymity in the online discussions may encourage the participants to speak more freely. As these data are directly entered by the participants this data collection method is time efficient. However, another advantage of the online focus group we performed was the asynchronous form. This form could sometimes hamper direct discussion, as there is sometimes a long time between reactions and often participants are not online at the same time. However, on the other hand, the asynchronous communication really enables patients to participate at times suitable 
Koster, E.S., Philbert, D., Dijk, L. van, Vries, T.W. de, Bouvy, M.L. “I just forget to take it”: asthma self-management needs and preferences in adolescents. Journal of Asthma: 2015, 52(8), 831-837

for them, which might be especially important for adolescents with busy schedules. The online focus group format might be more suitable for older children or adolescents as in our study older participants were more actively involved and provided more comments. Furthermore, in line with previous research in a pediatric population [31], younger participants tended to direct their answers more directly to the moderators instead of reacting to other participants' comments. In addition, older participants seemed to be more actively involved in the (both the online and conventional) focus groups. Overall, respondents valued participation in the study for both the online and the traditional focus groups.

Limitations of our study include: low recruitment rate and a relatively small sample size. Furthermore, the sample originated mainly from a Dutch native population. First, the number of participants was relatively small, as is the case for most qualitative studies $[6,17,20]$, and this limitation is shared with other studies in adolescent populations as previous studies also described the challenges of participation of adolescents in health research and resulting small sample sizes $[32,33]$. Another limitation of the study is that information was collected in focus groups that comprised of adolescents who were mainly of Dutch native origin and may therefore not reflect views of other racial or ethnic groups of teenagers. Differences may exist in health outcomes between racial or ethnic groups $[34,35]$. The above-discussed limitations may affect external validity (generalizability). However, the majority of findings reported during the focus groups were observed across all three groups for adolescents for various ages included through primary and secondary care, supporting the validity of findings. Thus, despite these limitations, this study gives an increased knowledge of the major themes that adolescents' with asthma face with respect to asthma self-management.

\section{CONCLUSION}

Many participants mentioned forgetting to take medication as reason for nonadherence. Interventions in this group should therefore at least be aimed at this practical unintentional non-adherence behavior and should by modifiable to needs and preferences of individual patients. A smartphone application seems most promising for this target population.

\section{Everybody has their own way of doing things}

(girl, aged 16, traditional focus group)

\section{Declaration of interest}

This study was funded by an unrestricted research grant from the Royal Dutch Pharmacists Association (KNMP). The authors report no conflict of interest related to the study.

\section{REFERENCES}


Koster, E.S., Philbert, D., Dijk, L. van, Vries, T.W. de, Bouvy, M.L. “I just forget to take it”: asthma self-management needs and preferences in adolescents. Journal of Asthma: 2015, 52(8), 831-837

1. Koster ES, Raaijmakers JA, Vijverberg SJ, Maitland-van der Zee AH. Inhaled corticosteroid adherence in paediatric patients: the PACMAN cohort study. Pharmacoepidemiol Drug Saf 2011;20:1064-1072

2. Menckeberg TT, Bouvy ML, Bracke M, Kaptein AA, Leufkens HG, Raaijmakers JA, Horne R. Beliefs about medicines predict refill adherence to inhaled corticosteroids. J Psychosom Res 2008;64:47-54

3. Desai M, Oppenheimer JJ. Medication adherence in the asthmatic child and adolescent. Curr Allergy Asthma Rep 2011;11:454-464

4. Orrell-Valente JK, Jarlsberg LG, Hill LG, Cabana MD. At what age do children start taking daily asthma medicines on their own? Pediatrics 2008;122:e1186-1192

5. Lasmar L, Camargos P, Champs NS, Fonseca MT, Fontes MJ, Ibiapina C, Alvim C, Moura JA. Adherence rate to inhaled corticosteroids and their impact on asthma control. Allergy 2009;64:784-789

6. Brinkman WB, Sherman SN, Zmitrovich AR, Visscher MO, Crosby LE, Phelan KJ, Donovan EF. In their own words: adolescent views on ADHD and their evolving role managing medication. Acad Pediatr 2012;12:53-61

7. Hugtenburg JG, Timmers L, Elders PJ, Vervloet M, van Dijk L. Definitions, variants, and causes of nonadherence with medication: a challenge for tailored interventions. Patient Prefer Adherence 2013;7:675-682

8. Nickels A, Dimov V. Innovations in technology: social media and mobile technology in the care of adolescents with asthma. Curr Allergy Asthma Rep 2012;12:607-612

9. Petrie KJ, Perry K, Broadbent E, Weinman J. A text message programme designed to modify patients' illness and treatment beliefs improves self-reported adherence to asthma preventer medication. Br J Health Psychol 2012;17:74-84

10. Vervloet M, Linn AJ, van Weert JC, de Bakker DH, Bouvy ML, van Dijk L. The effectiveness of interventions using electronic reminders to improve adherence to chronic medication: a systematic review of the literature. J Am Med Inform Assoc 2012;19:696-704

11. DeShazo J, Harris L, Pratt W. Effective intervention or child's play? A review of video games for diabetes education. Diabetes Technol Ther 2010;12:815-822

12. Dean AJ, Walters J, Hall A. A systematic review of interventions to enhance medication adherence in children and adolescents with chronic illness. Arch Dis Child 2010;95:717-723

13. Stewart M, Letourneau N, Masuda JR, Anderson S, McGhan S. Impacts of online peer support for children with asthma and allergies: it just helps you every time you can't breathe well. J Pediatr Nurs 2013 2013;28:439-452

14. Salema NE, Elliott RA, Glazebrook C. A systematic review of adherence-enhancing interventions in adolescents taking long-term medicines. J Adolesc Health 2011;49:455-466

15. Panzera AD, Schneider TK, Martinasek MP, Lindenberger JH, Couluris M, Bryant CA, McDermott RJ. Adolescent asthma self-management: patient and parentcaregiver perspectives on using social media to improve care. J Sch Health 2013;83:921-930

16. Nordfeldt S, Angarne-Lindberg T, Nordwall M, Ekberg J, Bertero C. As facts and chats go online, what is important for adolescents with type 1 diabetes? PLoS One 2013;8:e67659

17. Dennison L, Morrison L, Conway G, Yardley L. Opportunities and challenges for smartphone applications in supporting health behavior change: qualitative study. $\mathrm{J}$ Med Internet Res 2013;15:e86

18. Rikkers-Mutsaerts ER, Winters AE, Bakker MJ, van Stel HF, van der Meer V, de Jongste JC, Sont JK; SMASHING Study Group. Internet-based self-management compared with usual care in adolescents with asthma: a randomized controlled trial. Pediatr Pulmonol 2012;47:1170-1179

19. Koster ES, Blom L, Philbert D, Rump W, Bouvy ML. The Utrecht pharmacy practice network for education and research: a network of community and hospital pharmacies in the Netherlands. Int J Clin Pharm 2014;36:669-674 
Koster, E.S., Philbert, D., Dijk, L. van, Vries, T.W. de, Bouvy, M.L. "I just forget to take it": asthma self-management needs and preferences in adolescents. Journal of Asthma: 2015, 52(8), 831-837

20. Tates K, Zwaanswijk M, Otten R, van Dulmen S, Hoogerbrugge PM, Kamps WA Bensing JM. Online focus groups as a tool to collect data in hard-to-include populations: examples from paediatric oncology. BMC Med Res Methodol 2009;9:15

21. Koster ES, Philbert D, Winters NA, Bouvy ML. Medication adherence in adolescents in current practice: Community pharmacy staff's opinions. Int J Pharm Pract 2014;23:221-224

22. Stewart M, Letourneau N, Masuda JR, Anderson S, Cicutto L, McGhan S, Watt S. Support needs and preferences of young adolescents with asthma and allergies: just no one really seems to understand. J Pediatr Nurs 2012;27:479-490

23. Braun V, Clarke V. Using thematic analysis in psychology. Qual Res Psychol 2006;3:77-101

24. Hommel KA, Odell S, Sander E, Baldassano RN, Barg FK. Treatment adherence in paediatric inflammatory bowel disease: perceptions from adolescent patients and their families. Health Soc Care Community 2011;19:80-88

25. MacDonell K, Naar-King S, Huszti H, Belzer M. Barriers to medication adherence in behaviorally and perinatally infected youth living with HIV. AIDS Behav 2013;17:8693

26. Hanghoj S, Boisen KA. Self-reported barriers to medication adherence among chronically ill adolescents: a systematic review. J Adolesc Health 2014;54:121-138

27. van der Meer V, van Stel HF, Detmar SB, Otten W, Sterk PJ, Sont JK. Internetbased self-management offers an opportunity to achieve better asthma control in adolescents. Chest 2007;132:112-119

28. Boulos MN, Brewer AC, Karimkhani C, Buller DB, Dellavalle RP. Mobile medical and health apps: State of the art, concerns, regulatory control and certification. Online J Public Health Inform 2014;5:229

29. Mulvaney SA, Ho YX, Cala CM, Chen Q, Nian H, Patterson BL, Johnson KB. Assessing adolescent asthma symptoms and adherence using mobile phones. J Med Internet Res 2013;15:e141

30. Peterson-Sweeney K. The use of focus groups in pediatric and adolescent research. J Pediatr Health Care 2005;19:104-110

31. Zwaanswijk M, Tates K, van Dulmen S, Hoogerbrugge PM, Kamps WA, Bensing JM. Young patients', parents', and survivors' communication preferences in paediatric oncology: results of online focus groups. BMC Pediatr 2007;7:35

32. Koster ES, Philbert D, Winters NA, Bouvy ML. Adolescents' inhaled corticosteroid adherence: the importance of treatment perceptions and medication knowledge. $\mathrm{J}$ Asthma 2014;5:1-6

33. McDonagh JE, Bateman B. Nothing about us without us: considerations for research involving young people. Arch Dis Child Educ Pract Ed 2012;97:55-60

34. Urbanus-van Laar JJ, de Koning JS, Klazinga NS, Stronks K. Suboptimal asthma care for immigrant children: results of an audit study. BMC Health Serv Res 2008;8:22

35. Vasbinder E, Dahhan N, Wolf B, Zoer J, Blankman E, Bosman D, van Dijk L, van den Bemt $P$. The association of ethnicity with electronically measured adherence to inhaled corticosteroids in children. Eur J Clin Pharmacol 2013;69:683-690 
Koster, E.S., Philbert, D., Dijk, L. van, Vries, T.W. de, Bouvy, M.L. “I just forget to take it”: asthma self-management needs and preferences in adolescents. Journal of Asthma: 2015, 52(8), 831-837

\section{TABLES}

Table 1. Questions/statements used during focus group sessions

\begin{tabular}{|c|c|c|}
\hline Topic & Online focus groups & Traditional focus group \\
\hline Astma - impact & * & $\begin{array}{l}\text { What impact does living with asthma have on your } \\
\text { daily life? }\end{array}$ \\
\hline Adherence - general & $\begin{array}{l}\text { Day 1: How often do you manage to use your asthma } \\
\text { medication (inhalation corticosteroids)? } \\
\text { Are there specific moments when you do or do not } \\
\text { succeed to use your asthma medication? }\end{array}$ & $\begin{array}{l}\text { It is difficult for me to use my medicines as prescribed } \\
\text { by the doctor } \\
\text { Are there specific moments when you do or do not } \\
\text { succeed to use your asthma medication? }\end{array}$ \\
\hline Role of parents & $\begin{array}{l}\text { Day 2: Do your parents play an important role in your } \\
\text { medication use? Why (not)? } \\
\text { Do you like to talk to doctors or nurses yourself or do } \\
\text { you prefer your parents do the talking? Do you pick } \\
\text { up your medicines in the pharmacy yourself? Is there } \\
\text { anyone else supporting you in your medication use? }\end{array}$ & $\begin{array}{l}\text { My parents play an important role in my medication } \\
\text { use. } \\
\text { Do you like to talk to doctors or nurses yourself or do } \\
\text { you prefer your parents do the talking? Do you pick } \\
\text { up your medicines in the pharmacy yourself? Is there } \\
\text { anyone else supporting you in your medication use? }\end{array}$ \\
\hline Role of healthcare provider & $*$ & $\begin{array}{l}\text { My pharmacist or physician plays an important role in } \\
\text { my medication use. }\end{array}$ \\
\hline Coping with medication use & $\begin{array}{l}\text { Day 3: Which things have you done to use your asthma } \\
\text { medication as best as you can? } \\
\text { Have you ever used any tools for example to remind } \\
\text { you? } \\
\text { Day } 4 \text { : What do you think are good ways to improve or } \\
\text { ease asthma medication use? } \\
\text { Where do you look for information about your medi- } \\
\text { cation when you want to know something? Do you } \\
\text { ever use online networks (social media) to discuss } \\
\text { your asthma or medication use? }\end{array}$ & $\begin{array}{l}\text { Which things have you done to use your asthma } \\
\text { medication as best as you can? } \\
\text { What are your suggestions for other patients? } \\
\text { Have you ever used any tools for example to remind } \\
\text { you? }\end{array}$ \\
\hline Tools & $\begin{array}{l}\text { Day 5: There are different tools to support people with } \\
\text { their disease or medication use, one example is } \\
\text { computer (health) games. For teenagers with diabetes } \\
\text { there is a special computer game in which you learn } \\
\text { more about the disease and correct use of medica- } \\
\text { tion. What do you think of such a computer game for } \\
\text { teenagers with asthma? } \\
\text { What could such a game look like? What elements } \\
\text { should be included? Do you think such a game could } \\
\text { be useful for you? }\end{array}$ & $\begin{array}{l}\text { There are different tools to support people with their } \\
\text { disease or medication use: } \\
\text { - computer (health) games } \\
\text { - smartphone app } \\
\text { - online networks/social media } \\
\text { - other } \\
\text { What do you think of these options for teenagers with } \\
\text { asthma? } \\
\text { What should such a tool look like? } \\
\text { What elements should be included? }\end{array}$ \\
\hline Other & Day 6 \& 7: Other questions/comments & Other questions/comments \\
\hline
\end{tabular}

Table 2. Characteristics population.

\begin{tabular}{|c|c|c|c|}
\hline & \multicolumn{2}{|c|}{$\begin{array}{c}\text { Online } \\
\text { focus group }\end{array}$} & \multirow{2}{*}{$\begin{array}{c}\text { Traditional } \\
\text { focus group } \\
\text { Young \& older } \\
\text { adolescents } \\
(n=7)\end{array}$} \\
\hline & $\begin{array}{c}\text { Young } \\
\text { adolescents } \\
(n=7)\end{array}$ & $\begin{array}{c}\text { Older } \\
\text { adolescents } \\
(n=7)\end{array}$ & \\
\hline Age, mean (range) & $12.4(12-13)$ & $14.4(14-16)$ & $14.4(12-16)$ \\
\hline Male gender, $n(\%)$ & $4(57.1)$ & $4(57.1)$ & $2(28.6)$ \\
\hline Dutch ethnicity, $n(\%)$ & $6(85.7)$ & $5(71.4)$ & $7(100)$ \\
\hline
\end{tabular}


Koster, E.S., Philbert, D., Dijk, L. van, Vries, T.W. de, Bouvy, M.L. "I just forget to take it": asthma self-management needs and preferences in adolescents. Journal of Asthma: 2015, 52(8), 831-837

Table 3. Perspectives regarding daily asthma self-management for young and older adolescents.

\begin{tabular}{lll}
\hline & \multicolumn{1}{c}{$\begin{array}{c}\text { Young adolescents (age 12-13) } \\
(n=9)\end{array}$} & \multicolumn{1}{c}{$\begin{array}{c}\text { Older adolescents (age 14-16) } \\
(n=12)\end{array}$} \\
\hline Reasons for non-adherence & Forgetting $(n=4)$ & $\begin{array}{l}\text { Forgetting }(n=6) \\
\text { Lack of (perceived) effect }(n=2) \\
\end{array}$ \\
& Lack of (perceived) effect $(n=3)$ & Difficult to use at school $(n=1)$ \\
Difficult to use at school $(n=1)$ & Reminding $(n=8)$ \\
& Reminding $(n=4)$ & Filling prescriptions at pharmacy $(n=5)$ \\
& Filling prescriptions at pharmacy $(n=4)$ & Joining at physician visits $(n=5)$ \\
& Joining at physician visits $(n=3)$ & I am independent $(n=2)$ \\
\hline
\end{tabular}

Each row may present the views of different patients.

Table 4. Perspectives regarding solutions to improve daily medication intake behavior.

\begin{tabular}{lll}
\hline & \multicolumn{1}{c}{$\begin{array}{c}\text { Young adolescents (age 12-13) } \\
(n=9)\end{array}$} & \multicolumn{1}{c}{$\begin{array}{c}\text { Older adolescents (age 14-16) } \\
(n=12)\end{array}$} \\
\hline $\begin{array}{l}\text { Coping with daily } \\
\text { medication regimen }\end{array}$ & $\begin{array}{l}\text { Nothing special }(n=4) \\
\text { I put my medicines in a fixed place }(n=2) \\
\text { Using an alarm }(n=1)\end{array}$ & $\begin{array}{l}\text { I put my medicines in a fixed place }(n=9) \\
\text { Nothing special }(n=2) \\
\text { I always take my medicines with me }(n=1)\end{array}$ \\
$\begin{array}{l}\text { I always take my medicines with me }(n=1) \\
\text { Solutions to improve } \\
\text { adherence }\end{array}$ & $\begin{array}{l}\text { Reducing the number of intake moments }(n=2) \\
\text { Game not useful }(n=4)\end{array}$ & $\begin{array}{l}\text { Game not useful }(n=8) \\
\text { App }(n=4)\end{array}$ \\
& Game might be useful $(n=3)$ & $\begin{array}{l}\text { Whatsapp }(n=4) \\
\text { Game might be useful }(n=2) \\
\end{array}$ \\
& App $(n=1)$ & Movies $(n=2)$ \\
& Use of social media $(n=1)$
\end{tabular}

Each row may present the views of different patients. 